\title{
Qualidade de vida no trabalho de profissionais do NASF no município de São Paulo
}

I ${ }^{1}$ Denise Fernandes Leite, ${ }^{2}$ Débora Dupas Gonçalves do Nascimento,

${ }^{3}$ Maria Amélia de Campos Oliveira I

Resumo: A apreensão e a análise da Qualidade de Vida no Trabalho (QVT) dos profissionais do Núcleo de Apoio à Saúde da Família (NASF) são de extrema importância, uma vez que a implantação dessa equipe é recente e seu processo de trabalho desenvolve-se numa lógica contra-hegemônica de trabalho em saúde. Este estudo procurou identificar as percepções acerca da QVT dos profissionais das equipes de NASF que atuam no município de São Paulo, bem como os aspectos facilitadores e dificultadores por eles identificados no cotidiano do trabalho. Trata-se de um estudo qualitativo, de natureza descritiva e exploratória, realizado em Unidades Básicas de Saúde da Família, com uma equipe do NASF de cada uma das cinco Coordenadorias Regionais de Saúde do município de São Paulo: Leste, Centro-Oeste, Norte, Sudeste e Sul. Foram realizadas 40 entrevistas, cuja análise de conteúdo revelou quatro núcleos de sentido relacionados à percepção e à avaliação da qualidade de vida no trabalho dos profissionais: (1) infraestrutura para o trabalho; (2) sobrecarga e qualidade de vida no trabalho; (3) autonomia e identificação com o trabalho; (4) trabalho em equipe e relacionamento interpessoal. O processo de trabalho do NASF vem sendo modificado e reestruturado desde sua implantação, conforme as particularidades e necessidades locais. Envolve diversas questôes que afetam diretamente a QVT, podendo até repercutir negativamente na qualidade do serviço prestado. Os profissionais do NASF e seu fazer cotidiano requerem um olhar ampliado da gestão e dos demais atores envolvidos, em prol de uma melhor QTV e, consequentemente, de uma minimização de insatisfação, adoecimentos, afastamentos e estresse ocupacional.

\author{
1 Departamento de \\ Planejamento e Regulação da \\ Provisão de Profissionais da \\ Saúde, Secretaria de Gestão \\ do Trabalho e da Educação na \\ Saúde, Ministério da Saúde \\ (DEPREPS/SGTES/MS). Brasília- \\ DF, Brasil. Endereço eletrônico: \\ denisefernandess@gmail.com \\ ${ }^{2}$ Doutoranda do Programa \\ Interunidades de Doutoramento \\ em Enfermagem da Escola de \\ Enfermagem da USP e da Escola \\ de Enfermagem de Ribeirão \\ Preto, Universidade de São \\ Paulo. São Paulo e Ribeirão \\ Preto-SP, Brasil. Endereço \\ eletrônico:ddupas@uol.com.br \\ ${ }^{3}$ Professora titular, \\ Departamento de Enfermagem \\ em Saúde Coletiva da Escola \\ de Enfermagem, Universidade \\ de São Paulo. São Paulo-SP, \\ Brasil. Endereço eletrônico: \\ macampos@usp.br
}




\section{Introdução}

O Núcleo de Apoio a Saúde da Família (NASF), instituído por meio da Portaria $\mathrm{n}^{\mathrm{o}} 154$ de 24 de janeiro de 2008, tem como objetivo apoiar as equipes da Estratégia Saúde da Família (ESF), visando à atuação conjunta e ao desenvolvimento de novas práticas em saúde (BRASIL, 2009). Busca-se a corresponsabilização e a gestão integrada do cuidado, por meio de atendimentos compartilhados com as equipes da ESF, e projetos terapêuticos que envolvam os usuários e que sejam capazes de considerar a singularidade dos sujeitos. Utilizam-se ferramentas validadas pela Política Nacional de Humanização, ou seja, a clínica ampliada, o apoio matricial e o projeto terapêutico singular (NASCIMENTO; OLIVEIRA, 2010).

Um dos maiores entraves para a implantação e a efetivação desse modelo de atenção e do novo paradigma proposto para essa equipe de apoio é a formação dos profissionais de saúde com ênfase na assistência e nas especialidades, não atendendo às necessidades do Sistema Único de Saúde - SUS (SCALCO et al., 2010).

$\mathrm{O}$ atual contexto da formação não atende as necessidades e vulnerabilidades identificadas nos diversos territórios de atuação do SUS, atrelado aos atuais modelos de atenção. Requer dos profissionais uma visão menos fragmentada e singular das necessidades em saúde. $\mathrm{O}$ descompasso entre a formação e o requerido no cotidiano de atuação gera insegurança e conflitos no ambiente de trabalho, sofrimento, adoecimento, com consequente impacto na qualidade de vida no trabalho (QVT).

Em seu processo de trabalho, os profissionais do NASF deparam-se cotidianamente com diversas situações geradoras de estresse e sofrimento, como a dificuldade de aceitação do modelo de atenção proposto pelas equipes da ESF, gestores e usuários, a compreensão do papel de "apoio", o uso de novas tecnologias de cuidado em saúde e o despreparo dos profissionais (ESF e NASF) para atuar em equipe na perspectiva $\mathrm{da}$ interdisciplinaridade. Todas essas dificuldades podem comprometer a qualidade da assistência e a QVT.

Existem diversas concepções de QVT, que vão desde o enfoque clínico (ausência de doenças em âmbito pessoal), até conceitos relativos à exigência de recursos, objetos e procedimentos de natureza gerencial e estratégica no nível das organizações (LIMONGI-FRANÇA; ARELLANO, 2002). Reconhece-se, todavia, que a insatisfação e a incompreensão vivenciadas no processo de trabalho 
podem desencadear alterações emocionais que geram mudanças no estilo de vida dos trabalhadores, podendo interferir na capacidade de execução de tarefas cotidianas e por vezes provocar doenças.

A apreensão da percepção da QVT dos profissionais do NASF e sua análise são de extrema importância, uma vez que a implantação dessa equipe de apoio é recente e seu processo de trabalho desenvolve-se numa lógica contra-hegemônica de trabalho em saúde. A identificação de aspectos geradores de estresse e sofrimento psíquico em decorrência do trabalho e suas formas de organização devem ser identificadas, monitoradas e avaliadas, a fim de subsidiar reestruturações locais e até nacionais.

Considerando a complexidade das açôes desenvolvidas, a diversidade territorial, a responsabilidade dos profissionais que compóem a equipe do NASF e a carência de estudos sobre a temática, esta investigação buscou identificar e analisar as percepções sobre QVT de profissionais das equipes de NASF que atuam no município de São Paulo, bem como os aspectos facilitadores e dificultadores por eles identificados no cotidiano do trabalho.

\section{Método}

\section{Tipo do estudo}

Estudo qualitativo, de natureza descritiva e exploratória. A abordagem qualitativa foi eleita por se tratar de um método que melhor se aplica ao estudo de relações, representações, crenças, percepções e opiniōes, produtos das interpretações que os indivíduos fazem a respeito de como vivem, constroem artefatos e a si mesmos. Além disso, essa abordagem é mais adequada às investigações de grupos e segmentos delimitados e focalizados, e também para análises de discursos e documentos (MINAYO, 2006). O estudo é descritivo por buscar descrever fatos ou fenômenos, procurando explorar e aprofundar seu estudo nos limites de uma realidade específica (TRIVIÑOS, 1987).

\section{Local}

A coleta dos dados foi realizada em uma Unidade Básica de Saúde (UBS) com ESF de cada uma das cinco Coordenadorias Regionais de Saúde (CRS) do município de São Paulo: Leste, Centro-Oeste, Norte, Sudeste e Sul. 
Até outubro de 2010 o município de São Paulo contava 256 UBS com ESF e 1.196 equipes de Saúde da Família, distribuídas nas cinco coordenadorias de saúde: Leste - 55 UBS e 245 equipes; Centro-Oeste - 23 UBS e 92 equipes; Norte - 43 UBS e 197 equipes; Sudeste - 45 UBS e 196 equipes; Sul - 90 UBS e 466 equipes (SÃO PAULO, 2012).

\section{Sujeitos}

Os sujeitos do estudo foram profissionais de uma das equipes do NASF de cada uma das cinco CRS do município de São Paulo. A escolha da equipe foi realizada de forma aleatória, por meio de sorteio das unidades que constavam do Cadastro Nacional de Estabelecimentos de Saúde (CNES) em julho de 2011.

Os profissionais do NASF que compunham as equipes sorteadas totalizaram 47 pessoas. Entretanto, sete não participaram do estudo devido a incompatibilidade das agendas ou por estarem de férias no momento da coleta de dados. Dos 40 profissionais entrevistados (85,2\%), 09 pertenciam à CRS Leste, 07 à Norte, 12 à Centro-Oeste, 06 à Sudeste e 06 à CRS Sul.

\section{Coleta de dados}

A coleta de dados foi realizada no período de agosto a outubro de 2011, tendo sido usado um roteiro semiestruturado de entrevista elaborado especificamente para esse fim e ajustado com a aplicação de um pré-teste com uma equipe de NASF que não foi incluída no estudo. Foram abordadas questões relacionadas à percepção e à avaliação do profissional sobre seu trabalho e as repercussões sobre sua qualidade de vida. As entrevistas foram agendadas previamente por contato telefônico, realizadas individualmente nas unidades-sede de cada equipe, gravadas e transcritas integralmente.

\section{Procedimentos analíticos}

O material empírico resultante da transcrição das entrevistas foi submetido a análise de conteúdo. Trata-se de um conjunto de técnicas de análise das comunicações que utiliza procedimentos sistemáticos e objetivos de descrição do conteúdo das mensagens, por meio de indicadores, quantitativos ou não. Sua intenção é a inferência de conhecimentos relativos às condições de produção e recepção das mensagens (BARDIN, 1977). 
O projeto foi submetido ao Comitê de Ética em Pesquisa da Secretaria Municipal de Saúde do Município de São Paulo, tendo sido aprovado sob o parecer de no 214/11. Algumas coordenadorias de saúde solicitaram apresentação dos objetivos do estudo previamente à realização das entrevistas. Todos os participantes assinaram o Termo de Consentimento Livre e Esclarecido, conforme preconiza a Resolução no 196/96 do Conselho Nacional de Saúde, vigente à época de realização do estudo.

\section{Resultados}

Dos 40 profissionais entrevistados, 31 eram do sexo feminino, e a média de suas idades foi de 32,4 anos. Quanto ao tempo de formação, a média foi de 8,67 anos, sendo que 12 profissionais haviam realizado pós-graduação latu ou strictu sensu nas áreas de Saúde Pública, Saúde Coletiva ou Saúde da Família.

O tempo médio de atuação na equipe do NASF foi de 1,81 ano. Dentre as categorias profissionais, 8 eram fisioterapeutas, 5 terapeutas ocupacionais, 5 fonoaudiólogos, 3 nutricionistas, 4 educadores físicos, 5 psicólogos, 4 assistentes sociais, 1 farmacêutico, 2 ginecologistas, 1 psiquiatra, 1 geriatra, e 1 pediatra.

O número de UBS e de equipes da ESF apoiadas pelas equipes do NASF que foram entrevistadas em cada região foi: Leste - 3 UBS e 10 equipes; CentroOeste - 2 UBS e 9 equipes; Norte -4 UBS e 18 equipes; Sudeste - 4 UBS e 17 equipes; Sul - 3 UBS e 19 equipes.

A análise de conteúdo revelou quatro núcleos de sentido relacionados à percepção e à avaliação da QVT: 1) infraestrutura para o trabalho; 2) sobrecarga e qualidade de vida no trabalho; 3) autonomia e identificação com o trabalho; 4) trabalho em equipe e relacionamento interpessoal, abordados a seguir.

\section{Infraestrutura para o trabalho}

Os entrevistados mencionaram a infraestrutura como um dos aspectos fundamentais para o desenvolvimento do trabalho. Consideraram boa a infraestrutura quando as UBS conseguem se organizar para disponibilizar espaço físico para os profissionais do NASF dentro das unidades, principalmente salas para atendimentos, grupos e reuniões, e também recursos materiais, como acesso a computadores e materiais para práticas corporais/atividades físicas, que foram os mais enfatizados. 

no cotidiano de sua prática e, consequentemente, na QVT:

[...] E ter infraestrutura para trabalhar, porque às vezes a gente idealiza muitas coisas, mas não consegue colocar em prática. Isso traz uma certa frustração [...]. Por exemplo, uma coisa que dificulta: a gente não tem acesso ao computador, a gente não tem uma sala e isso tudo tem que ser muito bem negociado.

[...] é relatório, é capacitação que a gente não consegue fazer nas unidades, então, a gente não tem um computador disponível, a gente não tem uma sala disponível [...]. Tudo isso implica para ter uma qualidade de vida.

A parte às vezes do espaço físico, materiais que poderiam facilitar muito... o que a gente trabalha é o que a gente improvisa. [...] então, a gente utiliza o que a gente tem no território, [...] bastão, a gente fala pra pessoa trazer sempre cabo de vassoura, garrafinha descartável. Talvez se a gente tivesse as questôes de materiais em si, facilitaria também bastante o trabalho.

A falta de espaço físico para a realização do trabalho dos profissionais do NASF é um dos motivos para a busca de recursos e equipamentos no território. Porém, nem sempre o território consegue suprir a necessidade de um espaço específico para o desenvolvimento das ações. Essa questão estrutural interfere na QVT, como demonstra o discurso de alguns dos entrevistados:

[...] lógico, a gente acaba indo na comunidade, fazendo grupos. Faço grupo em igrejas, faço grupos no clube-escola, mas, mesmo assim, você também precisa do espaço dentro da unidade. As unidades não estavam preparadas pra esse tipo de crescimento, de repente e de uma vez chegam oito, nove profissionais. Eu acho que isso também vai influenciar de uma forma. Se você não tem esse preparo, e a maioria das nossas unidades não tem, a gente disputa salas, a gente divide, a gente tem que jogar a todo momento ali com horários, com agendas, com boa vontade também. E acho que isso influencia de uma forma negativa a QVT.

[...] aqui a gente tem algumas questões que dificultam muito o trabalho, a questão de espaço nas unidades. Para conseguir articular todo movimento para conseguir fazer nossas ações, é muito complicado, por conta de espaço físico mesmo, de sala, de ter onde fazer. A gente usa bastante os espaços da comunidade, das associações, igrejas, mas algumas consultas clínicas, que precisam dessa intervenção clínica, ficam bem prejudicadas, porque a gente acaba ficando meio cigano, cada dia tem que ficar correndo atrás de sala [...]. É uma coisa que desgasta muito e que, se fosse melhor organizada, eu acho que pouparia muito tempo e energia. Então, eu acho que isso prejudica a qualidade de vida no trabalho.

Mas eu acho que é uma coisa que dificulta, por exemplo, você vai fazer um grupo, você não tem uma sala adequada pra fazer o grupo, aí você tem que ficar se deslocando... é, a gente fica tentando usar recursos próximos da comunidade, mas nem sempre é tão próximo assim. 
O profissional que trabalha no NASF apresenta em seu cotidiano de trabalho algumas particularidades que podem conduzir ao estresse e, consequentemente, à sobrecarga, o que pode afetar sua QVT. Entre elas, destacam-se a falta de entendimento por parte das equipes sobre a finalidade do NASF, a carga horária de trabalho e o despreparo profissionais para atuar na ESF. O comprometimento na QVT a partir da dinâmica do trabalho também foi relacionado à falta de apoio institucional:

Olha, eu acredito que neste momento nós não temos qualidade de vida porque a gente cuida tanto e somos esquecidos de nos cuidar, nós somos muito esquecidos...

[...] Então, hoje eu chego num momento muito cansada e eu acho que... eu vejo isso acontecer com muita gente também, de estar no mesmo processo, de sair do NASF, de não aguentar esse trabalho mais e ir para outro. Para mim, eu estou muito cansada, eu não tenho vontade de sair, mas eu tenho vontade de tirar dois meses de férias, para esquecer um pouco e tirar a cabeça do trabalho.

Alguns verbalizaram que o processo de trabalho em que estão inseridos é "adoecedor", pois se deparam com situação de grande vulnerabilidade, com uma grande demanda para atendimento, devido a falhas na rede assistencial:

Ela não é boa hoje, ela é "adoecedora”, haja vista as infecções urinárias de repetição. Entendeu? A afonia, 4 dias sem conseguir falar... Eu acho que tem uma sobrecarga muito grande. Existe um grande empenho do profissional para estudar, para continuar se aperfeiçoando, para interagir e exercer as devidas responsabilidades. E a contrapartida, ela é tão falha às vezes, e isso não depende do líder direto, depende também da instituição, e isso não acontece. Então, hoje o processo de trabalho é "adoecedor". Eu me questiono: Quanto tempo eu vou permanecer no NASF? E por que existe tanta rotatividade dentro do NASF? Isso é uma coisa comum.

Trabalhar no NASF é muito complicado, porque são regiōes muito vulneráveis, a violência, o tráfico. [...] não tem como te dizer se de fato nós temos qualidade de vida.

[...] está pesado [...] a demanda é muito grande, então, mesmo que a gente se utilize de técnicas que facilitem [...]. Depois de você ver as dificuldades de encaminhamento, as coisas que você inicia e você precisa de um braço que não vem, isso cansa.

[...] eu acho que são casos muito complexos que a gente enfrenta aqui, o dia a dia é muito pesado, porque tudo que a equipe não consegue dar conta, ela acaba trazendo pra gente.

A carga horária de trabalho também foi um aspecto mencionado, uma vez que a diferença de carga horária entre os profissionais da mesma equipe também dificulta a interação e a realização de atividades compartilhadas. Para os 
profissionais que têm dois vínculos, ou seja, trabalham em duas equipes NASF, o estresse e a sobrecarga são ainda maiores:

Tem uma diferença grande entre os profissionais de 4 e os profissionais de 8 horas. $\mathrm{O}$ processo de trabalho do profissional de 4 horas, muitas vezes, é mais dificultoso. Porque a gente, apesar de ter um volume teoricamente menor, os processos e os grupos têm de acontecer da mesma forma [...] É muito complicado conseguir dar conta das demandas das equipes, na sua especialidade, em 4 horas. Então, os processos muitas vezes... Se eu tivesse que definir, eu definiria como sofrido para o profissional, para que ele consiga cumprir todas as suas responsabilidades.

Acho que outra coisa também do processo de trabalho que existe e isso acaba colocando algumas questões, que é a questão de você ter profissionais com carga horária diferente. Então, você precisa de um profissional da manhã e um da tarde para mesma categoria e eles não se encontram, porque um sai, tem uma hora de almoço, o outro entra e não tem nem como não ter nem meia hora juntos, a não ser que faça banco de horas, e isso é uma coisa que você não pode ficar gerando. Então, não é institucionalizado esse encontro. Isso fragmenta o trabalho, dificulta você conseguir ter uma coesão na equipe, ter uma coesão no direcionamento do trabalho, porque quando você não tem esses espaços para discussão, para discutir, dialogar, dividir, eu acho que isso complica também o processo de trabalho.

Eu acho que é péssima. Hoje, estando em dois NASF, eu acho que é péssima, no trabalho, minha qualidade de vida no trabalho. Então, eu acho que... não do trabalho, né, é qualidade no trabalho. Eu acho que é péssima. Eu chego com 2 anos e 3 meses de NASF estressadíssima, eu acho que eu estou esgotada do trabalho aqui, agora. [...] eu acho que o trabalho em dois trabalhos é muito pesado, dois NASF é mais ainda [...]

\title{
O desejo de ter uma carga horária de trabalho menor também foi apontado como um fator que melhoraria a qualidade de vida do profissional:
}

[...] eu acredito que melhorou, depois das 30 horas, a minha qualidade melhorou. Embora o trabalho não diminuiu [sic], porque a carga horária diminuiu, mas a demanda não, mas é... Melhorou a qualidade, a minha qualidade de vida, então, eu consigo, eu acho que trabalhar melhor.

Eu gostaria só de trabalhar menos horas, porque eu acho que é muito puxado trabalhar 40 horas nesse ritmo... É uma coisa também que eu sinto muita falta, que também, digamos assim, piorou um pouco a minha qualidade de vida foi por conta do tempo mesmo, não ter tanto tempo para estudar e realizar outras atividades que eu gostava muito $[\ldots]$

\section{Autonomia e identificação com o trabalho}

\author{
Para alguns, o trabalho no NASF possibilitou amadurecimento pessoal e profissional \\ em decorrência do exercício da autonomia e do enfrentamento das adversidades no
}


discursos, ela está implícita nas falas, assim como a percepção de amadurecimento pelo e no trabalho, assim como a autonomia, como fator que colabora para que haja QVT. Também estão presentes as ideias de adaptação, flexibilidade e mudança por meio da experiência adquirida no dia a dia do trabalho:

Olha, eu estou há três anos e eu acho que mudou muito, acho que mudou principalmente porque eu revi meus objetivos dentro do trabalho [...] Eu acho que a gente melhorou, porque eu melhorei, eu mudei a minha forma, digamos, de pensar. Não é externo, é interno.

Eu acho que é pesado, eu acho que é bem pesado... acho que com o tempo, eu já tenho aí 6 anos de formada, a gente vai ficando... vai tendo alguns instrumentos, algumas técnicas que vão ajudando a gente a se prevenir, a se fortalecer, a conseguir olhar para algumas coisas que talvez antes eu tinha mais dificuldade, ficava um pouco mais desesperada, ansiosa, angustiada... Hoje eu já consigo lidar um pouco melhor.

Olha, a minha qualidade de vida hoje, é... eu acho que é boa, porque eu acho que a gente tem uma coisa que poucos têm, que é a autonomia. [...] Eu ainda tenho uma autonomia do meu trabalho, da minha função e das minhas atividades. Então, eu consigo planejar um pouco mais esse trabalho, o trabalho que eu exerço.

[...] Acho que trabalhar com liberdade, dentro dos limites que a instituição permite, mas trabalhar com liberdade, acho que isso é qualidade de vida no trabalho.

Então, geralmente o nosso trabalho tem esse viés da relação e da parte organizacional, que nem sempre funciona [...]. São muitas equipes, a gente tem que o tempo inteiro estar se adaptando.

A própria experiência, eu acho que é um facilitador, eu tenho bastante tempo já de formada, passei por várias experiências diferentes, é a primeira em PSF [Programa de Saúde da Família]. Então a gente vai criando essa experiência que vai facilitando.

A satisfação pessoal com o trabalho também foi referida como positiva para a qualidade de vida. Foi ressaltada a importância da identificação com o trabalho e de "gostar do que faz", mesmo diante das dificuldades:

Não diria ruim, mais ou menos. [...] A qualidade de vida não é ruim porque eu faço o que eu gosto e eu tento trazer o melhor no meu trabalho, mas ela não é boa por conta dessa correria.

Hoje? Olha, a minha qualidade de vida no trabalho... eu acho que ela seria assim, de média para boa, porque, apesar de todos esses empecilhos [...] eu gosto muito do trabalho, e por mais desafios que tenha e mais coisas que deem errado, se a gente planeja e não dá certo, não consegue fazer. Eu vejo também, ao mesmo tempo, bastante... muitas coisas que dão certo, eu vejo bastante resultado também, por outro lado. Então é uma coisa que me faz feliz, apesar dos empecilhos, é uma coisa que me faz feliz. 
Eu acho que é você primeiro se identificar com o trabalho, porque independente da demanda, das dificuldades que tem com o trabalho, que acho que todo trabalho tem, eu acho que passa por uma identificação, né. Então, se eu me identifico com a possibilidade de me sentir útil e de me sentir... daquele trabalho fazer sentido para mim, e eu acho que passa pela a sua avaliação pessoal, de dentro e para fora dessa identificação, a gente poder ter um ajuste dessas duas coisas [...]

Embora não estivesse prevista no roteiro de entrevista a quantificação da QVT por meio de uma nota, alguns profissionais espontaneamente o fizeram:

Tem categorias? Notas? Posso dar uma nota de 0 a 10 ? Então, de 0 a 10 , eu acho que é... 6.

Mas, se eu fosse fazer um balanço, se eu fosse te dar uma nota, por exemplo, de QV e a nota fosse, por exemplo, de 1 a 5 , eu sei lá, daria 2,5 , não chega a 3 , sabe?

Bom, de 0 a 10, pensando em tudo isso que eu falei, eu colocaria 6, tirando 4 da questão de ambiente, de estrutura física e de material. Relacionamento com as outras pessoas, com os outros profissionais, pensando nesse relacionamento profissional mesmo, é o que eleva a nota, é o que faz com que ela não seja mais baixa. Mas pensando em ambiente físico, em material, pra mim é 6 .

\section{Trabalho em equipe e relacionamento interpessoal}

$\mathrm{O}$ trabalho em equipe e o relacionamento interpessoal dentro da equipe do NASF com as demais equipes da ESF foram expostos pelos entrevistados como aspectos importantes para a QVT, tanto positivo quanto negativo. Entre os aspectos positivos foram apontados o apoio, a retaguarda, o trabalho conjunto e o suporte dentro da equipe. E como aspectos negativos, a dificuldade de trabalhar em equipe e a falta de flexibilidade dos profissionais.

O relacionamento interpessoal e a interação por meio do diálogo e da proximidade, não apenas entre a equipe do NASF, mas com os demais envolvidos no processo, como as equipes da ESF e a gerência da UBS, foram considerados indispensáveis para a QVT:

Olha, pontos positivos que eu vejo é que, por exemplo, a minha equipe, eu avalio como uma equipe que me dá suporte, que me dá a retaguarda, [...] que caminha junto, porque nós estamos juntos. Eu acho que isso faz com que a minha qualidade de vida tenha um ponto positivo.

[...] em termos de relacionamento com a equipe, dentro da equipe NASF e fora, eu acho que é boa a minha qualidade sim, eu acho que é muito boa. Eu consigo dialogar bem com todo mundo. Claro que tem pessoas que são mais próximas, pessoas mais distantes, pessoas com quem você se identifica mais e menos, mas de uma maneira geral eu acho que é uma boa qualidade de vida, eu me sinto bem aqui. 
Eu acho que, em primeiro lugar, é ter uma boa relação dentro da própria equipe

NASF e com as UBS que a gente trabalha, porque se a gente não tem uma interação legal, a gente não tem vontade de vir trabalhar e não é prazeroso, e aí não tem nenhuma qualidade, aí, tudo fica ruim, nada acontece, né... E acho que é isso mesmo, um relacionamento, uma boa interação, um relacionamento dentro das equipes, não só NASF, mas também das equipes de saúde da família, gerência da UBS.

Respeito, tolerância, compreensão, adaptação, flexibilidade e empatia com os demais profissionais também foram mencionados como aspectos que têm implicações para a QVT:

Ah, eu acho que QVT, uma boa QVT, é se dar bem com as pessoas, ter respeito, tolerância, saber que o outro é diferente, saber conversar, eu acho que é essas coisas assim... compreender, acho que isso faz a gente ter uma boa QVT.

[...] É... empatia, afinidades, o tempo todo, com os médicos, com os ACS... Então isso não depende muito do processo de trabalho, depende de como cada um entra com seu potencial ou suas próprias características como pessoa e enquanto profissional.

[...] e se você estiver muito certo de qual é o seu papel e tiver um vínculo bacana entre as unidades, entre as pessoas, e tiver flexibilidade para se adaptar, porque aí você tem que lidar com aquilo que é seu papel e aquilo que as pessoas querem, a demanda das equipes. [...] Se você tiver dificuldade com isso, de verdade, eu não recomendo ir para o NASF, vai fazer reabilitação. Não que seja maior ou menor [...]. Mas a flexibilidade é o que vai te facilitar ou te ferrar no trabalho.

A importância das relações, a proximidade com os demais profissionais da equipe e a construção do trabalho multiprofissional, interdisciplinar e até transdisciplinar no cotidiano do trabalho do NASF também foram citados por alguns dos entrevistados:

[...] acho que depende de cada equipe de NASF, mas... Você poder estar com os profissionais, é uma equipe multiprofissional, acho que isso é muito interessante, você tem várias visões em vários ângulos daquela mesma situação. Então, isso é um ponto muito positivo tanto para você agir no dia a dia como para sua aprendizagem. É muito legal isso, o trabalho em equipe e multiprofissional.

Então, esse trabalho multiprofissional, a gente tenta fazer o máximo possível para ele se tornar bem transdisciplinar. A gente fala que é uma troca de conhecimento, de informações, para se poder chegar num objetivo, né, e precisa de bastante aproximação.

Contudo, alguns entrevistados ressaltaram que, apesar de todos os benefícios já citados do trabalho em equipe, há também o fato de ser um trabalho muito difícil, pois nem sempre os integrantes dessa equipe ou das equipes ESF estão dispostos a trabalhar em conjunto, e isso influencia o trabalho a ser desenvolvido e o resultado final: 
[...] Então, eu diria que falando em qualidade de vida hoje para o meu trabalho, às vezes o que eu sinto é que cansa um pouco, que é estressante essa coisa do trabalho em equipe, que como eu falei inicialmente. É muito bom, é muito gostoso, mas também, ao mesmo tempo em que é bom e é gostoso, é difícil, não é fácil. Então, nesse aspecto eu acho que é o que mais prejudica minha qualidade de vida hoje no trabalho. Às vezes uns problemas de relacionamento entre as equipes [...]

[...] você precisa sempre trabalhar em equipe, e isso é muito difícil para todo mundo. [...] Então, acho que como a gente está sempre precisando trabalhar em equipe, trabalhar junto com outros profissionais, e nem sempre as pessoas estão dispostas a isso, então isso influencia um pouquinho na sua qualidade de vida no seu trabalho. [...] de repente, o profissional [...] tem dificuldade de trabalhar em equipe, então, isso dificulta o trabalho.

\section{Discussão}

Assim como as percepções dos trabalhadores sobre a própria definição de qualidade de vida e QVT, o processo de trabalho do NASF não é uniforme nos diversos contextos. Para melhor compreender os resultados obtidos, vale ressaltar algumas particularidades da estruturação da gestão da saúde no município de São Paulo, bem como as características e as particularidades da atuação do NASF em diversos territórios.

No município de São Paulo, a Secretaria Municipal de Saúde tem contratos de gestão e convênios com instituiçôes parceiras (organizaçôes sociais), que são entidades privadas sem fins lucrativos que administram alguns órgãos ou serviços de saúde. São essas instituições que assumem a contratação dos profissionais da atenção primária, assim como seu treinamento, coordenação e acompanhamento (BOUSQUAT et al., 2006).

A implantação da ESF no município iniciou-se em 1996 com o projeto QUALIS - Qualidade Integral em Saúde, por meio da parceria entre Ministério da Saúde, Secretaria de Estado da Saúde e duas Organizações Sociais de Saúde. Esse projeto atendia a população em unidades de saúde sob a gestão do Estado, de acordo com os princípios e diretrizes do SUS, nos moldes do Programa Saúde da Família (SÃO PAULO, 2012; NASCIMENTO, 2008). Em 2001, com a municipalização do Sistema de Saúde, as Unidades de Saúde e os profissionais do então QUALIS passaram para a gestão da Secretaria Municipal de Saúde e foi implantado o PSF por meio de convênios estabelecidos com Instituições da Sociedade Civil (SÃO PAULO, 2012). 
Com o passar dos anos, a implantação da ESF foi crescente, assim como os resultados nos indicadores de saúde. Dez anos depois, São Paulo contava com 1.196 equipes de ESF, distribuídas em 256 UBS, o que representava uma cobertura de $43,3 \%$ da população do município. A meta prevista para 2012 envolvia a implantação de 1.224 equipes, aumentando a cobertura para 44,3\% (SÃO PAULO, 2012).

A ESF tem alcançado bons resultados em diversas regiōes do país. Porém, verifica-se que para alcançar a integralidade da atenção e a interdisciplinaridade das ações, colaborando para o aumento da resolubilidade na Atenção Básica, fazse necessária a presença de outros profissionais da saúde integrando as equipes da ESF (NASCIMENTO; OLIVEIRA, 2010).

Assim, o Ministério da Saúde criou os NASF, por meio da Portaria GM no 154, de 24 de janeiro de 2008, refirmada na portaria GM no 2488, de 21 de outubro de 2011. Tais núcleos têm como objetivo apoiar a inserção da ESF na rede de serviços e ampliar a abrangência, a resolutividade, a territorialização e a regionalização, bem como a ampliação das ações da Atenção Básica.

No município de São Paulo, a implantação dos NASF nas cinco CRS teve início em julho de 2008. Até outubro de 2010, havia 86 equipes desenvolvendo o apoio à ESF (SÃO PAULO, 2012). De acordo com as portarias GM no 154 , de 24 de janeiro de 2008, e GM no 2488, de 21 de outubro de 2011, as equipes de NASF classificavam-se em duas modalidades: NASF 1 e NASF 2. Cada NASF 1 deveria realizar suas atividades vinculada a no mínimo 8 (oito) e no máximo 15 (quinze) equipes da ESF, e cada NASF 2, vinculada a no mínimo 3 (três) e no máximo 7 (sete) equipes.

Em 28 de dezembro de 2012, foi publicada a Portaria GM no 3124, que redefiniu os parâmetros de vinculação dos NASF nas modalidades 1 e 2 às equipes ESF ou equipes de Atenção Básica para populaçōes específicas, e criou a modalidade NASF 3. Atualmente cada NASF 1 deve estar vinculada a no mínimo 5 (cinco) e no máximo 9 (nove) equipes de ESF e equipes de Atenção Básica, enquanto a modalidade NASF 2 deve vincular-se a no mínimo 3 (três) e a no máximo 4 (quatro) equipes. A nova modalidade NASF 3 deve estar vinculado a no mínimo 1 (uma) e a no máximo 2 (duas) equipes ESF ou equipes de Atenção Básica.

No período de coleta dos dados, as equipes realizavam o apoio conforme a Portaria no 2488, enquadradas na modalidade NASF 1 . Recentemente, com a 
publicação da Portaria GM no 3124, estas e as demais equipes do município estão em processo de reorganização e adequação às novas diretrizes.

Ao contrário do modelo tradicional de prestação de cuidados, centrado na assistência curativa, especializada, medicamentosa, fragmentada e individual, que tem no hospital o lócus de solução de todo e qualquer problema de saúde, o novo modelo proposto por ESF e NASF luta para substituir a forma de pensar e praticar saúde, priorizando o enfoque coletivo e a ação interprofissional centrada na família e na coletividade (COSTA et al., 2009).

O cotidiano do processo de trabalho do NASF vem sendo modificado e reestruturado desde sua implantação, conforme as particularidades e as necessidades de cada região. Envolve diversas questôes, entre as quais as que afetam diretamente a QVT dos profissionais, podendo repercutir negativamente na qualidade do serviço prestado.

Um estudo que abordou a infraestrutura e recursos para o trabalho na Atenção Básica constatou que a insatisfação em relação às condições dos recursos materiais disponíveis e a escassez de material nas UBS foi considerada pelos trabalhadores como um fator de desgaste físico e mental (CAMELO; ANGERAMI, 2007). A falta de estrutura física também já foi associada a dificuldades para a realização das atividades na Atenção Básica (FORMIGA; RIBEIRO, 2012). Uma das dificuldades citadas pelos profissionais de Educação Física no NASF para a realização das atividades consistiu justamente na ausência de espaços adequados (SOUZA; LOCH, 2011).

No presente estudo, tanto a estrutura física como a disponibilidade de materiais e equipamento foram citados como aspectos importantes para a valorização do profissional e promoção de sua QVT no NASF. A falta desses recursos dificulta e algumas vezes até impossibilita a realização das atividades.

Com a chegada dos profissionais do NASF nas UBS, agravou-se a falta de espaço físico para o desenvolvimento do trabalho, que já era uma problemática em alguns contextos, e isso desencadeou uma busca por recursos e equipamentos do território para o desenvolvimento das ações.

A experiência profissional na organização de equipes de saúde da família mostrou que o fato de desenvolver múltiplas tarefas com um alto grau de exigências e responsabilidades e que dependem do ambiente, da organização do trabalho e 
do preparo para exercer seu papel, pode criar tensão para o trabalhador, a equipe e a coletividade assistida. Nesse tipo de atividade, em que a realidade do indivíduo fica muito próxima, os problemas são de diversas ordens e as limitações são incontáveis, expondo muitas vezes o profissional a riscos que podem desencadear estresse ocupacional e outros transtornos (CAMELO; ANGERAMI, 2007).

Em meio às exigências internas e externas do processo de trabalho na ESF, e até mesmo de usuários e famílias assistidas, os trabalhadores se veem sem condiçōes de absorver a imensa cota de responsabilidades que lhes é conferida. Isso causa sensações de incompetência, cansaço, sofrimento e desgaste, as quais interferem sobremaneira no processo de viver humano, prejudicando a QVT (AZAMBUJA et al., 2007).

A interação profissional é fortemente influenciada pelos valores e pela cultura construídos ao longo do tempo, sendo, portanto, socialmente produzida e estando em constante mutação. A história e as experiências de vida, bem como as relações com os outros, vão conformando processos de subjetivação moldados principalmente pelo trabalho como experiência que transforma e produz novas formas de entender e agir no mundo e com o outro (LACAZ et al., 2010).

$\mathrm{O}$ processo de trabalho no NASF, como uma equipe de apoio, exige do profissional formação sólida e maturidade profissional para propor e estruturar ações de forma autônoma e responsável. Essas ações devem estar atreladas às necessidades e ao perfil epidemiológico dos diversos territórios, o que exige o monitoramento contínuo e avaliação junto às equipes da ESF, a fim de adequar as estratégias, quantas vezes sejam necessárias, em prol dos usuários e equipes. Isso implica o desenvolvimento da resiliência e da capacidade de lidar com frustrações e com a diversidade de opinióes e condutas que advêm do trabalho em equipe.

A resiliência e a maturidade profissional são caracterizadas pela capacidade de responder às demandas da vida cotidiana de maneira positiva, apesar das adversidades enfrentadas. Para isso, faz-se necessário compreender que cada indivíduo tem seu modo próprio de ser e atuar no mundo e que as relações interpessoais são processos dinâmicos, que mudam com as experiências acumuladas (NORONHA et al, 2009).

A promoção da QVT pode ser compreendida como um programa que visa facilitar e satisfazer as necessidades do trabalhador ao desenvolver suas 
atividades numa organização, tendo como base o fato de que as pessoas são mais produtivas quanto mais estiverem satisfeitas e envolvidas com o próprio trabalho (CONTE, 2003).

O trabalho em uma equipe multiprofissional é uma modalidade de trabalho coletivo que se configura na relação recíproca entre as diversas intervençōes técnicas e na interação de pessoas de diferentes áreas profissionais. E é por meio da comunicação que se dá a articulação das ações multiprofissionais e a cooperação (PEDUZZI, 2001). A articulação dos saberes resultante da interação comunicativa e horizontal é um requisito indispensável no cotidiano do trabalho em equipe com vistas à interdisciplinaridade (NASCIMENTO; OLIVEIRA, 2010).

Cada vez mais, as pessoas estão em busca de autoconhecimento e de maior entendimento daqueles com quem convivem. Tal fato revela um dos aspectos do comportamento humano, de buscar uma melhor compreensão de como as pessoas vivem e resolvem seus problemas dentro do seu contexto de trabalho (JOB, 2003). O trabalho consome uma parte considerável do tempo na vida das pessoas e pode ser uma fonte geradora de estresse e desgaste devido à sobrecarga e ao comprometimento demandado, o que por vezes diminui o tempo destinado às outras esferas do viver humano (AZAMBUJA et al., 2007).

No presente estudo, verificou-se que os profissionais do NASF com jornada de 8 horas diárias queixam-se principalmente de falta de tempo para a realização de outras atividades importantes para sua qualidade de vida. Já os que trabalham com jornada de 4 horas diárias referem que uma das suas dificuldades é justamente conseguir realizar tantas atividades em um período curto de tempo. Dessa forma, talvez seja necessário rever e repensar o processo de trabalho como um todo, para que se possa alcançar certo equilíbrio em relação à jornada de trabalho e à qualidade de vida do profissional do NASF.

\section{Considerações finais}

O estudo revelou que a infraestrutura para o trabalho, a maturidade e a autonomia profissional, a sobrecarga, a satisfação e a identificação com o trabalho, o trabalho em equipe e o relacionamento interpessoal foram aspectos que tanto podem facilitar como dificultar o cotidiano do trabalho e, consequentemente, afetar a QVT. O trabalho das equipes do NASF, que é recente e ainda passa por modificações e processos de adequação, necessita de um olhar ampliado, bem 
como de reflexôes para o desenvolvimento de ações em prol da qualidade de

vida, minimizando a insatisfação, os adoecimentos, os afastamentos e o estresse ocupacional, melhorando assim a QVT. ${ }^{1}$

\section{Referências}

AZAMBUJA, E. P. et al. Significados do trabalho no processo de viver de trabalhadoras de um programa de saúde da família. Texto Contexto Enferm, v. 16, n. 1, p. 71-9, jan-mar 2007. BARDIN, L. Análise de conteúdo. Lisboa: Ediçōes 70, 1977.

BOUSQUAT, A.; COHN, A.; ELIAS, P. E. A. Implantação do Programa Saúde da Família e exclusão socioespacial no Município de São Paulo, Brasil. Cad. Saúde Pública, v. 22, p. 1935-43, 2006.

BRASIL, Ministério da Saúde. Portaria GM n.154, de 24 de janeiro de 2008. Cria os núcleos de Apoio à Saúde da Família - NASF. Brasília: Diário Oficial da União, 25 Jan 2008.

. Portaria GM no 2488, de 21 de outubro de 2011. Aprova a Política Nacional de Atenção Básica, estabelecendo a revisão de diretrizes e normas para a organização da Atenção Básica, para a Estratégia Saúde da Família (ESF) e o Programa de Agentes Comunitários de Saúde (PACS). Diário Oficial da União 24 out. 2011.

. Portaria GM no 3124, de 28 de dezembro de 2012. Redefine os parâmetros de vinculação dos Núcleos de Apoio à Saúde da Família (NASF) Modalidades 1 e 2 às Equipes Saúde da Família e/ou Equipes de Atenção Básica para populaçôes específicas, cria a Modalidade NASF 3, e dá outras providências. Diário Oficial da União 31 dez. 2012.

. Secretaria de Atenção à Saúde. Política Nacional de Humanização da Atenção e Gestão do SUS. O HumanizaSUS na atenção básica / Ministério da Saúde, Secretaria de Atenção à Saúde, Política Nacional de Humanização da Atenção e Gestão do SUS. Brasília: Ministério da Saúde, 2009.

. Secretaria de Atenção à Saúde. Departamento de Atenção Básica e Departamento de Ações Programáticas Estratégicas. Cadernos de Atenção Básica; n. 27. Diretrizes do NASF (Núcleo de Apoio a Saúde da Família). Brasília: Ministério da Saúde, 2009.

CAMELO, S. H. H.; ANGERAMI, E. L. S. Riscos psicossociais relacionados ao estresse no trabalho das Equipes de Saúde da Família: percepçōes dos profissionais. Rev. Enferm. UERJ, v. 15, n. 4, p.502-7, 2007.

CONTE, A. L. Funcionários com qualidade de vida no trabalho são mais felizes e produzem mais. Revista FAE Business, n.7, nov. 2003.

COSTA, G. D. et al. Saúde da família: desafios no processo de reorientação do modelo assistencial. Rev. Bras. Enferm., v. 62, n. 1, p. 113-8, 2009. 
FORMIGA, N. F. B.; RIBEIRO, K. S. Q. S. Inserção do fisioterapeuta na Atenção Básica: uma Analogia entre Experiências Acadêmicas e a Proposta dos Núcleos de Apoio à Saúde da Família (NASF). Rev. Bras. Ciências da Saúde, v. 16, n. 2, p. 113-122, 2012.

JOB, F. P. P. Resiliência na organização: estudo de caso da medição e avaliação da resiliência de indivíduos em uma organização industrial. Rev. Fac. Ciênc. Méd. Sorocaba, v. 5, n. 1, p. 33-42, 2003.

LACAZ, F. A. C. et al. Qualidade de vida, gestão do trabalho e plano de carreira como tecnologista em saúde na atenção básica do Sistema Único de Saúde em São Paulo, Brasil. Cad. Saúde Pública, Rio de Janeiro, v. 26, n. 2, p. 253-263, fev. 2010.

LIMONGI-FRANÇA, A. C.; ARELLANO, E. B. As pessoas na organização. São Paulo: Editora Gente, 2002.

MINAYO, M. C. S. O desafio do conhecimento: pesquisa qualitativa em saúde. 9. ed. revista e aprimorada. São Paulo: Editora Hucitec, 2006.

NASCIMENTO, D. D. G; OLIVEIRA, M. A. C. Reflexões sobre as competências profissionais para o processo de trabalho nos Núcleos de Apoio à Saúde da Família. $O$ Mundo da Saúde, v. 34, n. 1, p. 92-96, 2010.

NORONHA, M. G. R. C. S. et al. Resiliência: nova perspectiva na Promoção da Saúde da Família? Ciência \& Saúde Coletiva, v. 14, n. 2, p. 497-506, 2009.

PEDUZZI M. Equipe multiprofissional de saúde: conceito e tipologia. Rev Saúde Pública, v. 35, n. 1, p. 103-9, 2001.

SCALCO, S. V. et al. Modelo para avaliação da gestão de recursos humanos em saúde. Cad. Saúde Pública, Rio de Janeiro, v. 26, n. 3, p. 603-614, mar. 2010.

SOUZA, S. C.; LOCH M. R. Intervenção do profissional de educação física nos Núcleos de Apoio à Saúde da Família em municípios do norte do Paraná. Revista Brasileira de Atividade Física \& Saúde, v. 16, n. 1, 2011.

TRIVIÑOS, A. N. S. Introdução à pesquisa em ciências sociais: a pesquisa qualitativa em educação. São Paulo: Atlas, 1987.

SÃO PAULO, Prefeitura de São Paulo. Secretaria Municipal de Saúde. Estratégia Saúde da Família - ESF. Atenção Básica. Disponível em: <http://www.prefeitura.sp.gov.br/cidade/ secretarias/saude/atencao_basica/esf/index.php?p=17783\#nasf>. Acesso em: 30 jan. 2012.

\section{Nota}

${ }^{1}$ D.F. Leite participou da concepção e planejamento do estudo; revisão bibliográfica; coleta, análise e interpretação dados; redação e revisão do artigo. D.D.G. Nascimento e M.A.C. Oliveira participaram do planejamento do estudo; análise e interpretação dos dados e revisão do artigo. 
Quality of life at work for NASF professionals working in the city of São Paulo

The apprehension and analysis of the Quality of Life at Work (QLW) of professionals working in the Family Health Support Center (NASF) are of utmost importance, since the implementation of this team is quite recent and its process of work developed into a logical counter-hegemonic for work in healthcare. This study sought to identify the perceptions of QLW of professionals of teams working in the NASF in São Paulo, as well as the advantages and constraints identified by them while performing their daily work. This is a qualitative study, of a descriptive and exploratory nature, conducted in Basic Family Health Units, with a team from the NASF from each of the five Regional Health Coordinators of the City of São Paulo: East, Midwest, North, Southeast and South. Forty (40) professionals were interviewed, with content analysis revealing, four clusters of meaning related to the perception and evaluation of the QLW (1) infrastructure for the work, (2) overload and QLW, (3) autonomy and identification with the work, (4) teamwork and interpersonal skills. The work process in the NASF has been modified and restructured since its implementation, according to the local needs and particularities. It involves several issues that directly affect the QLW and may even have a negative effect on the quality of service. The professionals of the NASF and its daily activities require an expanded management and other stakeholders, towards a better QLW and consequently minimizing dissatisfaction, illnesses, absenteeism and occupational stress.

$>$ Key words: family health support centers; quality of life at work; health care. 